\title{
A PERSPECTIVA DOS DOCENTES PARANAENSES SOBRE A GESTÃO DA ESCOLA BÁSICA*
}

Ângelo Ricardo de Souza*

Resumo: Este artigo expressa parte dos resultados de duas pesquisas convergentes que tratam da gestão da escola pública. A partir da análise de dados coletados em um survey realizado entre 2009 e 2010, o texto considera as distintas formas como os docentes da educação básica do estado do Paraná percebem as relações cotidianas com a gestão escolar. As conclusões do trabalho mostram como a experiência na docência e na vida política contribui para uma leitura mais crítica e democrática da gestão escolar.

Palavras-chave: Gestão escolar; Políticas educacionais; Trabalho docente.

Abstract: This article expresses part of two researches about public schools administration. Using data collected in a big survey (2009/2010), the text considers the teachers different perspectives of basic education in Paraná state about school administration. The findings indicate that experience in teaching work and in politics actions contributes for a critical and democratic perspective about school administration.

Keywords: School administration. Education policies. Teaching work. 


\section{Introdução}

A leitura sobre a realidade das escolas públicas paranaenses no que tange a sua gestão é o foco deste texto. Todavia, a tomada desta leitura é feita por meio da percepção que os docentes da educação básica, que atuam em escolas públicas estaduais e municipais no estado do Paraná, expressaram em um questionário específico aplicado nos anos de 2009 e 2010, por meio da pesquisa Trabalho Docente na Educação Básica no Brasil. Isto significa que as análises adiante desenvolvidas consideram o olhar dos docentes e, por isso mesmo, não podem se mostrar terminativas, ou seja, são análises ainda exploratórias, nas quais mais se levantam hipóteses explicativas do que conclusões finais.

Este estudo, como parte da pesquisa nacional, tomou os dados apenas dos docentes das escolas públicas da rede direta, excluindo-se, portanto, aqueles que atuam na rede conveniada e que também eram sujeitos da pesquisa nacional ${ }^{1}$. Assim, a tabela 01 mostra o público amostrado na pesquisa e cujas respostas ao questionário serão aqui analisadas.

Tabela 01 - Amostra pesquisada pela pesquisa TDEBB nas escolas da rede direta - Paraná

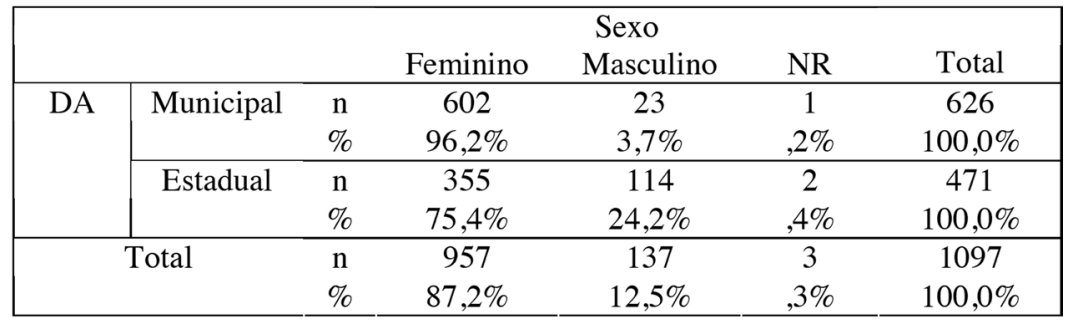

Fonte: Pesquisa TDEBB, 2009/2010. Obs.: NR= Não resposta, não se aplica, não sabe.

A busca para se compreender o fenômeno da gestão escolar, ainda que pela percepção dos docentes, se articula à ideia de que, para efeitos deste texto, a gestão escolar é tomada como processo político-pedagógico, para cuja compreensão há que se considerar que os respondentes dos questionários, os docentes, 
não iriam responder as perguntas sem considerar (mesmo que não conscientemente) o peso que as relações de poder têm no seu cotidiano. Isto é, sabe-se que um docente, ao analisar se a gestão da escola na qual atua é ou não democrática, o faz tomando como referência o peso das decisões cotidianas, da cultura organizacional, da governança e da governabilidade posta no ambiente escolar.

Com base nesta perspectiva sobre a gestão escolar, este estudo buscou analisar elementos concernentes à gestão escolar presentes no questionário da pesquisa mencionada cotejando-os com aspectos identificadores dos sujeitos de pesquisa. Assim, o leitor encontra nas linhas a seguir uma análise que buscou captar a percepção dos docentes sobre a gestão democrática em geral e, em especial, a construção do projeto político-pedagógico, a participação dos pais dos alunos na escola, a organização do conselho escolar e a avaliação dos docentes. Também se buscou observar a leitura dos docentes sobre a atuação do diretor escolar e a possível formação específica para tal atuação. Esses aspectos todos foram cotejados: a) à dependência administrativa, no intuito de se verificar se a percepção do docente cambiaria concernente ao fato de atuar em escola estadual ou municipal; b) ao tempo de trabalho na educação, na expectativa de que a experiência profissional poderia ter impacto sobre a percepção dos docentes acerca do fenômeno em tela; c) à experiência política, com a intenção de se avaliar se a trajetória em sindicatos ou partidos políticos poderia ter relação com a leitura que os docentes fazem da política escolar.

\section{A percepção dos docentes paranaenses sobre a gestão escolar}

Dentre os professores que atuam nas escolas municipais parece haver uma percepção de maior democracia do que os que atuam na rede estadual. Isto é curioso, pois as escolas estaduais paranaenses têm, sabidamente, uma tradição já consolidada da adoção de instrumentos de democratização da gestão escolar, 
como as eleições para diretores, o conselho escolar e a elaboração do projeto político-pedagógico. É possível que tal percepção mais elevada dentre os docentes das escolas municipais decorra da elevada representação, na amostra, de professores da rede municipal de Curitiba, na qual também se tem um desenvolvimento democrático da gestão escolar há mais de três décadas. Ademais, a despeito dos instrumentos democráticos, a prática da gestão escolar cambia a partir de variáveis as mais diversas e, assim, é possível que, mesmo com condições adequadas para o desenvolvimento da gestão democrática, a gestão não confirme tais condições.

Tabela 02- Percepção dos docentes paranaenses acerca da gestão democrática, por dependência administrativa

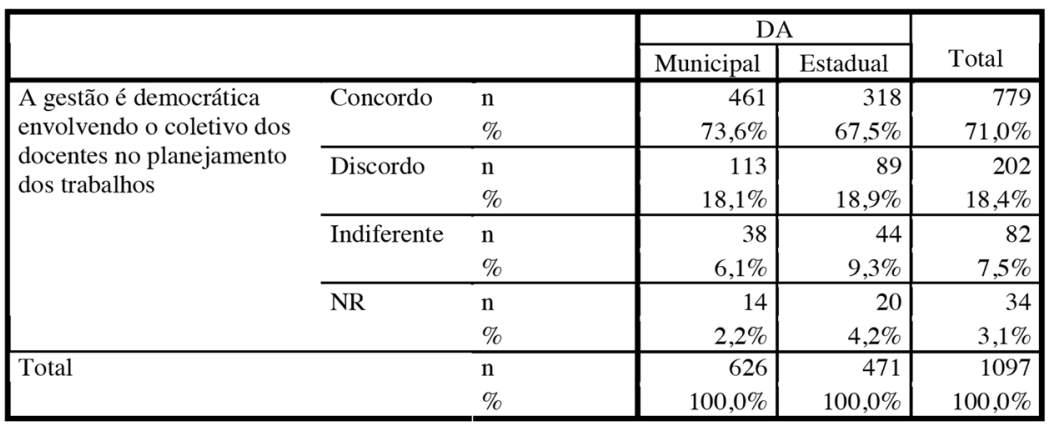

Fonte: Pesquisa TDEBB, 2009/2010. Obs.: NR = Não resposta, não se aplica, não sabe.

A percepção democrática dos docentes é também elevada em relação a um instrumento da gestão democrática, que é o projeto político-pedagógico (PPP), em especial no que tange à forma como foi construído, pois mais de $2 / 3$ dos respondentes avaliam que o PPP da escola em que trabalham é produto de um esforço coletivo e colaborativo. É possível que tal percepção seja elevada excessivamente, uma vez que, com isso, se reconhece não que em dois terços das escolas há um PPP, mas que, para além de existir, é efetivo e democrático. De outro lado, pode também representar o esforço feito em anos anteriores por educadores e dirigentes de sistemas de ensino, de colocar o PPP no centro das 
preocupações educacionais. Ou, ainda e quiçá mais provável, que o PPP é uma coisa um tanto difusa, materialmente pouco elaborada e conhecida, mas simbolicamente tida como importante e, assim, os docentes tendem a afirmar a sua existência e forma democrática de construção porque sabem que isso é o que deles se espera.

Tabela 03- Percepção dos docentes paranaenses sobre o Projeto Político-Pedagógico, por dependência administrativa

\begin{tabular}{|c|c|c|c|c|c|}
\hline & & & $\mathrm{D}$ & & \\
\hline & & & Municipal & Estadual & Total \\
\hline O projeto político- & Concordo & $\bar{n}$ & 417 & 301 & $\overline{718}$ \\
\hline pedagógico é resultado de & & $\%$ & $66,6 \%$ & $63,9 \%$ & $65,5 \%$ \\
\hline um trabalho coletivo e & Discordo & $\mathrm{n}$ & 135 & 99 & 234 \\
\hline & & $\%$ & $21,6 \%$ & $21,0 \%$ & $21,3 \%$ \\
\hline & Indiferente & $\mathrm{n}$ & 37 & 35 & 72 \\
\hline & & $\%$ & $5,9 \%$ & $7,4 \%$ & $6,6 \%$ \\
\hline & $\overline{\mathrm{NR}}$ & $\mathrm{n}$ & 37 & 36 & 73 \\
\hline & & $\%$ & $5,9 \%$ & $7,6 \%$ & $6,7 \%$ \\
\hline Total & & $\mathrm{n}$ & 626 & 471 & 1097 \\
\hline & & $\%$ & $100,0 \%$ & $100,0 \%$ & $100,0 \%$ \\
\hline
\end{tabular}

Fonte: Pesquisa TDEBB, 2009/2010. Obs.: NR = Não resposta, não se aplica, não sabe.

A gestão escolar recebe muita atenção quando se busca compreender as razões o (in)sucesso escolar, à ela são atribuídos os méritos e deméritos pelos resultados dos estudantes e pelo atendimento às mais distintas funções que se avaliem serem de responsabilidade da escola. Essa centralidade pode ter conexão com dois eixos, simultaneamente: a) o fato de se confundir gestão com direção, ou melhor, de se confundir o processo com o sujeito dirigente $\mathrm{e} b$ ) a perspectiva presidencialista que conduz boa parte das ações políticas no Brasil, de maneira que o dirigente escolar é encarado como uma espécie de "presidente" da escola.

Esses dois fatores parecem atuar conjuntamente à centralidade na figura do diretor e, com isto, a se reconhecer nele e, com isto, a se reforçar a imagem de forte liderança. A percepção sobre este fator é grande entre os docentes, pois $72 \%$ avaliam que a direção da escola onde atuam desempenha forte liderança. Todavia, essa percepção é um pouco menor nas escolas estaduais. As razões 
para tanto podem estar articuladas à autonomia (pedagógica, institucional) dos docentes que atuam nos anos finais do ensino fundamental e no ensino médio e/ou à distância que se encontra a escola do centro de poder no âmbito do sistema de ensino. Essa segunda hipótese sugere a ideia de que, como as escolas estaduais estão mais distantes hierárquica e institucionalmente da secretaria estadual de educação do que as escolas municipais em relação às secretarias municipais, a direção escolar pode ter mais autonomia e necessita operar menos como instrumento de pressão e controle sobre os trabalhadores. Ou seja, a direção é menos pressionada pelo sistema de ensino e a percepção sobre sua liderança tende a diminuir, uma vez que o diretor pode ser visto, neste caso, mais como um coordenador institucional do que como um "presidente" local.

Tabela 04- Percepção dos docentes paranaenses sobre a autoridade da direção escolar, por dependência administrativa

\begin{tabular}{|c|c|c|c|c|c|}
\hline & & & \multicolumn{2}{|c|}{$\overline{\mathrm{DA}}$} & \multirow[b]{2}{*}{ Total } \\
\hline & & & Municipal & Estadual & \\
\hline \multirow{8}{*}{$\begin{array}{l}\text { A administração/direção } \\
\text { exerce forte liderança sobre } \\
\text { o coletivo }\end{array}$} & Concordo & $\mathrm{n}$ & 484 & 306 & 790 \\
\hline & & $\%$ & $77,3 \%$ & $65,0 \%$ & $72,0 \%$ \\
\hline & Discordo & $\mathrm{n}$ & 96 & 104 & 200 \\
\hline & & $\%$ & $15,3 \%$ & $22,1 \%$ & $18,2 \%$ \\
\hline & Indiferente & $\mathrm{n}$ & 37 & 42 & 79 \\
\hline & & $\%$ & $5,9 \%$ & $8,9 \%$ & $7,2 \%$ \\
\hline & NR & $\mathrm{n}$ & 9 & 19 & 28 \\
\hline & & $\%$ & $1,4 \%$ & $4,0 \%$ & $2,6 \%$ \\
\hline \multirow[t]{2}{*}{ Total } & & $\mathrm{n}$ & 626 & 471 & 1097 \\
\hline & & $\%$ & $100,0 \%$ & $100,0 \%$ & $100,0 \%$ \\
\hline
\end{tabular}

Fonte: Pesquisa TDEBB, 2009/2010. Obs.: NR = Não resposta, não se aplica, não sabe.

Aquela segunda hipótese acerca da liderança do diretor parece ser corroborada pelos dados desta outra questão. O questionário perguntava aos docentes se eles avaliavam que o diretor passava a maior parte do tempo de trabalho lidando com questões de natureza administrativa. Ainda que a diferença não seja tão grande, aqui os docentes da rede estadual têm uma percepção de que isto ocorre, mas em relação aos professores municipais a percepção é menor. Tal prioridade administrativa pode estar 
articulada ao reconhecimento do controle sobre as relações de poder (Souza, 2012) e isso parece mais evidente entre os docentes das escolas municipais.

De qualquer maneira, não é tão elevada essa percepção, no geral, como outros estudos demonstram (Souza, 2007), podendo indicar que possivelmente os dirigentes escolares têm mudado um pouco o seu perfil, no sentido de demonstrar mais preocupação com questões de natureza pedagógica do que administrativa na escola.

Tabela 05- Percepção dos docentes paranaenses sobre o trabalho administrativo da direção escolar, por dependência administrativa

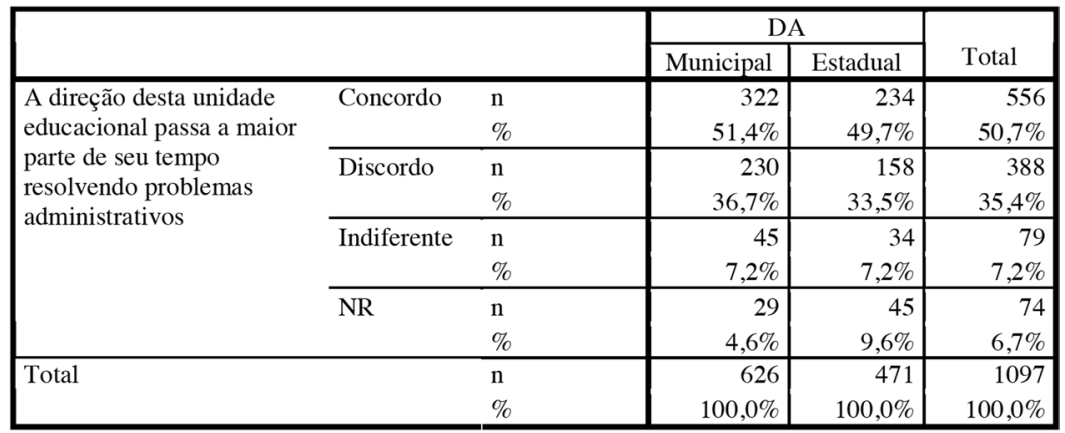

Fonte: Pesquisa TDEBB, 2009/2010. Obs: NR = Não resposta, não se aplica, não sabe.

A democracia cobra um tributo de participação dos cidadãos. Mais que isso, ela exige que a participação seja a mais significativa e ampliada possível, de maneira a que quanto mais quantificada e qualificada a participação, tanto mais democrática será uma instituição. Os docentes paranaenses avaliam que os familiares dos alunos não são muito participativos. Ao contrário, mais de $61 \%$ deles avalia que os pais não participam no sentido de contribuir com a gestão da escola. Essa percepção, mais uma vez, encontra diferenças entres os docentes municipais e os estaduais. Nas escolas da rede estadual, a participação dos pais parece ser ainda menor, pois apenas pouco mais de $13 \%$ dos docentes avalia tal participação como efetiva, enquanto que entre os professores municipais esse número chega a mais 
de $34 \%$. É certo que as escolas dos anos iniciais, de dominante oferta municipal, tendem a ter a família dos alunos mais próxima, inclusive porque lida com crianças, enquanto que as escolas dos anos finais do ensino fundamental e ensino médio (normalmente estaduais) tratam de alunos adolescentes e jovens, e essa divisão pode ter impacto na (não) presença da família na escola e, consequentemente, na percepção dos docentes das distintas dependências administrativas.

Tabela 06- Percepção dos docentes paranaenses sobre a participação dos pais na escola, por dependência administrativa

\begin{tabular}{|c|c|c|c|c|c|}
\hline & & & \multicolumn{2}{|c|}{$\mathrm{DA}$} & \multirow[b]{2}{*}{ Total } \\
\hline & & & Municipal & Estadual & \\
\hline \multirow{8}{*}{$\begin{array}{l}\text { Os pais de alunos são } \\
\text { bastante participativos e } \\
\text { contribuem na gestão dos } \\
\text { problemas cotidianos desta } \\
\text { unidade educacional }\end{array}$} & Concordo & $\mathrm{n}$ & 215 & 64 & 279 \\
\hline & & $\%$ & $34,3 \%$ & $13,6 \%$ & $25,4 \%$ \\
\hline & Discordo & $\mathrm{n}$ & 343 & 332 & 675 \\
\hline & & $\%$ & $54,8 \%$ & $70,5 \%$ & $61,5 \%$ \\
\hline & Indiferente & $\mathrm{n}$ & 56 & 52 & 108 \\
\hline & & $\%$ & $8,9 \%$ & $11,0 \%$ & $9,8 \%$ \\
\hline & NR & $\mathrm{n}$ & 12 & 23 & 35 \\
\hline & & $\%$ & $1,9 \%$ & $4,9 \%$ & $3,2 \%$ \\
\hline \multirow[t]{2}{*}{ Total } & & $\mathrm{n}$ & 626 & 471 & 1097 \\
\hline & & $\%$ & $100,0 \%$ & $100,0 \%$ & $100,0 \%$ \\
\hline
\end{tabular}

Fonte: Pesquisa TDEBB, 2009/2010. Obs.: NR = Não resposta, não se aplica, não sabe.

A participação demandada pela democracia envolve também os instrumentos internos da instituição escolar, em especial a sua principal ferramenta coletiva definida na legislação, que é o conselho escolar. Neste sentido, para metade dos docentes paranaenses, o conselho escolar tem se mostrado como uma eficiente ferramenta de gestão democrática. Mas, a diversidade entre as dependências administrativas é ainda mais acentuada nesta temática do que nas anteriores, pois, enquanto mais de $61 \%$ dos docentes municipais avaliam positivamente o conselho, menos de $35 \%$ dos estaduais compartilha desta visão. O que chama a atenção, neste caso, é também o elevado número de docentes estaduais para os quais é indiferente a composição e atuação do conselho escolar $(14,6 \%)$ e se somarmos este grupo aos que não quiseram ou não souberam responder $(18,7 \%)$ 
chega-se a mais de $33 \%$ da amostra dos docentes estaduais. Isso demonstra que nas escolas estaduais paranaenses ou o conselho escolar não é efetivo, ou ainda antes, inexistente em elevada proporção.

Nas escolas municipais, parece que o fator Curitiba desequilibra a amostra, pois o município (que responde por $76 \%$ da amostra dos docentes municipais) tem um programa consolidado de constituição de conselhos escolares e de formação continuada de conselheiros, além de contar com programas de transferência de recursos financeiros diretamente às escolas, exigindo o funcionamento do conselho para o recebimento e execução dos ditos recursos. Ainda assim, o sistema estadual de ensino tem, desde 1992, legislação que exige a constituição de conselhos em todas as escolas públicas e, portanto, já há tempo suficiente para que as escolas estaduais tivessem um perfil distinto deste aqui encontrado.

Tabela 7. Percepção dos docentes paranaenses sobre o conselho escolar, por dependência administrativa

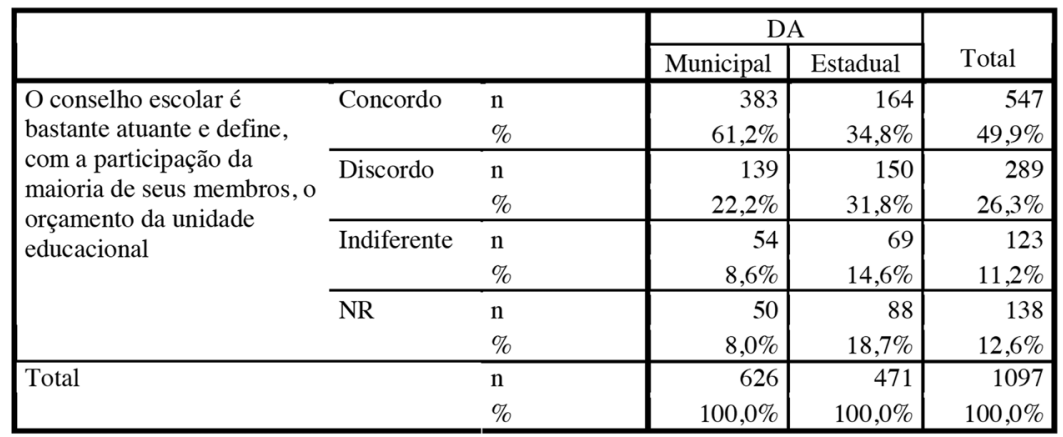

Fonte: Pesquisa TDEBB, 2009/2010. Obs.: NR = Não resposta, não se aplica, não sabe.

Um aspecto interessante e positivo encontrado na pesquisa mostra que a democracia parece ser mais justa e dissipadora de medos. Quando se analisa de maneira cruzada as variáveis sobre a percepção acerca da gestão democrática na escola cotejando-a com a possível necessidade do docente ser avaliado pela direção escolar, encontra-se um elevado grupo de docentes que 
considera que eles devem sim ser avaliados pela direção e que, ao mesmo tempo, avaliam que a gestão da escola na qual atuam é democrática. Isso pode sugerir que, uma vez que as relações de poder concernentes à gestão escolar estão mais horizontalizadas, os docentes não temem ser avaliados por seus chefes imediatos. Já aqueles docentes que discordam que sua escola seja democrática tendem também a discordar mais da ideia de serem avaliados pela chefia, pois, certamente, estão submetidos a um controle mais autoritário e verticalizado.

Tabela 08- Gestão democrática x Avaliação dos docentes pela direção escolar

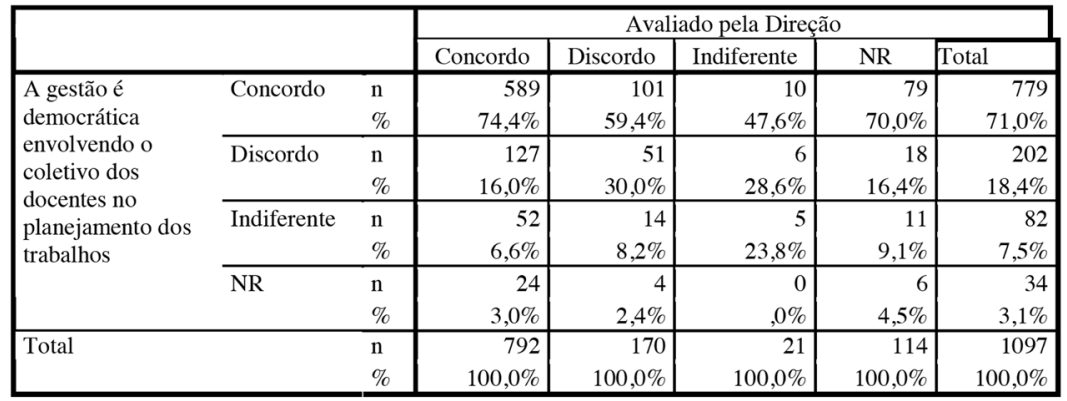

Fonte: Pesquisa TDEBB, 2009/2010. Obs.: NR = Não resposta, não se aplica, não sabe.

A leitura sobre a existência de uma gestão democrática na escola pública paranaense também muda de acordo com o grau de vivência política do docente ${ }^{2}$, mas os dados não apresentam qualquer possibilidade conclusiva a este respeito.

Quando se analisa cruzadamente a percepção sobre a gestão democrática e a filiação partidária, vê-se que os docentes filiados a algum partido político têm uma percepção de menor gestão democrática nas escolas nas quais atuam em relação aos docentes que não têm filiação partidária. Isso poderia provir da possível capacidade de uma leitura política mais completa por parte daqueles em relação a estes, dado que têm outras experiências (quiçá mais elaboradas) acerca da democracia.

Isso parece se reforçar quando são analisados os dados sobre filiação e atuação sindical, pois o grupo que apresenta menor 
percepção sobre a gestão democrática nas escolas é justamente aquele composto por professores sindicalizados e atuantes politicamente, corroborando aquela hipótese anterior acerca da criticidade desenvolvida a partir da experiência política. Contudo, os números não são tão distintos para se permitir conclusões mais peremptórias.

Tabela 09- Gestão democrática x Filiação partidária

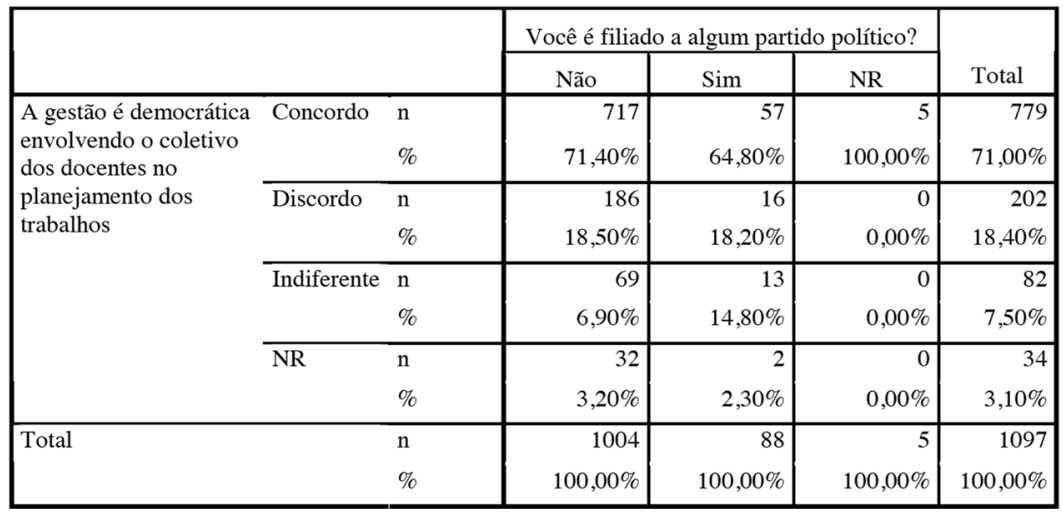

Fonte: Pesquisa TDEBB, 2009/2010. Obs.: NR = Não resposta, não se aplica, não sabe.

Tabela 10. Gestão democrática x Filiação e atuação sindical

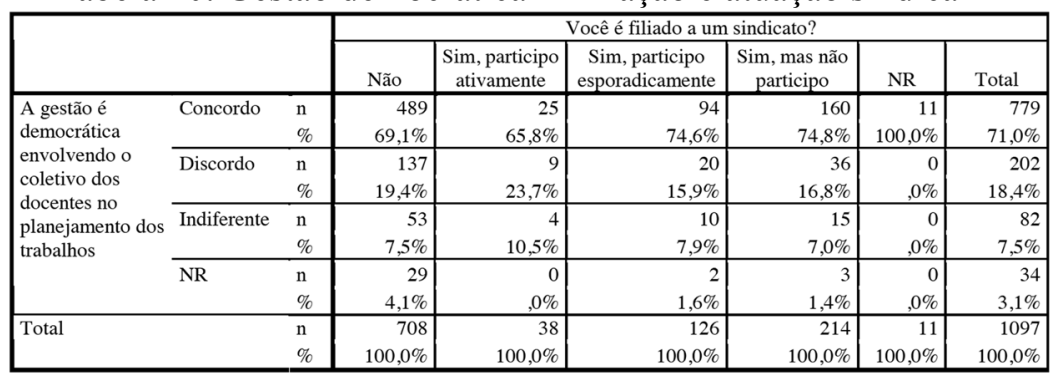

Fonte: Pesquisa TDEBB, 2009/2010. Obs.: NR = Não resposta, não se aplica, não sabe.

Um aspecto importante sobre a gestão escolar e que tem sido pauta inclusive de discussões no âmbito do novo Plano Nacional de Educação diz respeito à formação específica para a atuação na direção escolar. Os docentes da educação básica paranaenses avaliam, em uma ampla maioria, que os dirigentes escolares 
devem receber uma formação específica para sua respectiva função. Nas escolas municipais, tal percepção se aproxima de $90 \%$ da amostra e passa dos $80 \%$ entre os docentes estaduais. Todavia, estudos realizados em outros países (Littrell; Foster, 1995; Souza, 2008) têm mostrado que tal formação é secundária, sendo a formação pedagógica mais ampla aquela que potencializa a melhor ação do dirigente escolar, que desenvolve uma função que é predominantemente político-pedagógica (Souza, 2007). É possível se estabelecer duas linhas de raciocínio para se entender a posição dos docentes: a) os docentes consideram que uma função de comando/chefia/coordenação deve, burocraticamente, ser preenchida por alguém mais qualificado que a maioria e como a maioria tem formação pedagógica (de nível médio ou superior), incluindo o diretor, espera-se dele que tenha outra formação que o diferencie dos demais e/ou b) o diretor responde por uma função cuja natureza é mais administrativa do que pedagógica e, sendo assim, demanda ter uma formação para tal trabalho, a qual não lhe é fornecida na formação pedagógica básica. De qualquer forma, o que está subjacente a esta questão é que parece que os docentes avaliam que os diretores não são atualmente preparados para a sua função. De fato, parece que a formação inicial ou continuada de diretores escolares é um problema insuficientemente tratado (Teixeira, 2011).

Tabela 11- Formação específica para direção escolar por dependência administrativa

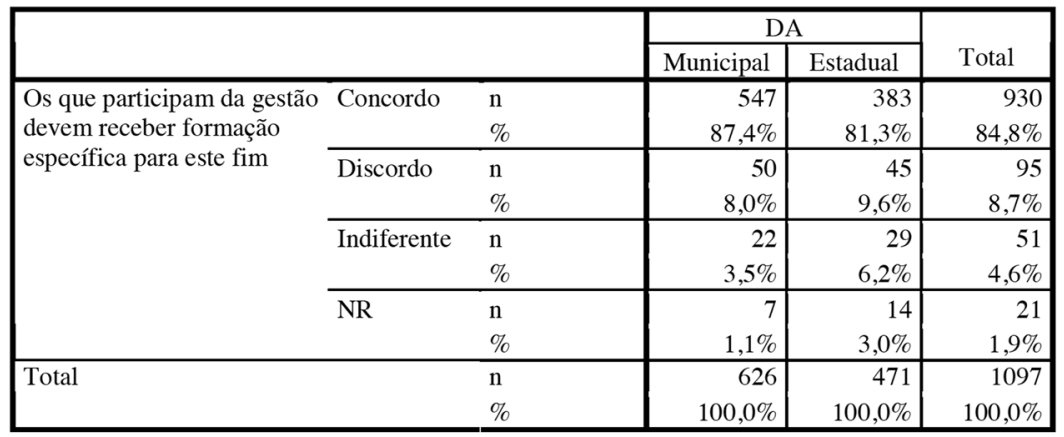

Fonte: Pesquisa 'IDEBB, 2009/2010. Obs.: NR = Não resposta, não se aplica, não sabe. 
E, por fim, um último aspecto a considerar se relaciona à percepção quanto à gestão democrática frente a experiência docente. Parece que os docentes que atuam há menos tempo na educação se mostram indiferentes ao fenômeno e na proporção em que se tornam mais experientes tendem inicialmente a se posicionar contrariamente, ou melhor, a avaliar que a gestão da escola onde atuam não é tão democrática e, quanto mais experientes, a avaliar a gestão como democrática.

Não são diferenças tão significativas, mas elas aparecem tanto na avaliação geral da gestão democrática quanto em relação a alguns de seus instrumentos, como é o caso do projeto político-pedagógico e da participação dos pais dos alunos. No que concerne ao conselho escolar, não parece haver diferença decorrente da experiência profissional do docente. Aquelas diferenças podem ser derivadas de uma maior criticidade dos mais jovens/menos experientes, ou de uma expectativa maior que os recém-formados tenham para com a gestão da escola, tendo em vista o que lhes é ensinado na universidade.

Tabela 12- Percepção sobre a gestão democrática por tempo de trabalho na educação

\begin{tabular}{|c|c|c|c|}
\hline $\begin{array}{l}\text { A gestão é democrática } \\
\text { envolvendo o coletivo dos } \\
\text { docentes no planejamento } \\
\text { dos trabalhos }\end{array}$ & $\begin{array}{c}\text { Tempo } \\
\text { médio de } \\
\text { trabalho na } \\
\text { educação }\end{array}$ & $\mathrm{N}$ & Desvio padrão \\
\hline Concordo & 13,4 & 778 & 9,1 \\
\hline Discordo & 12,0 & 202 & 8,6 \\
\hline Indiferente & 11,1 & 81 & 7,7 \\
\hline NR & 9,7 & 34 & 8,7 \\
\hline Total & 12,8 & 1095 & 8,9 \\
\hline
\end{tabular}

Fonte: Pesquisa TDEBB, 2009/2010. Obs.: NR = Não resposta, não se aplica, não sabe. 
Tabela 13- Percepção sobre o PPP por tempo de trabalho na educação

\begin{tabular}{|l|r|r|r|}
\hline $\begin{array}{l}\text { O projeto político- } \\
\text { pedagógico é resultado de } \\
\text { um trabalho coletivo e } \\
\text { colaborativo dos docentes }\end{array}$ & $\begin{array}{c}\text { Tempo } \\
\text { médio de } \\
\text { trabalho na } \\
\text { educação }\end{array}$ & \multicolumn{1}{|c|}{$\mathrm{N}$} & Desvio padrão \\
\hline Concordo & 13,3 & 716 & 9,0 \\
Discordo & 11,8 & 234 & 8,6 \\
Indiferente & 12,4 & 72 & 8,5 \\
NR & 11,9 & 73 & 8,7 \\
Total & 12,8 & 1095 & 8,9 \\
\hline
\end{tabular}

Fonte: Pesquisa TDEBB, 2009/2010. Obs.: NR = Não resposta, não se aplica, não sabe.

Tabela 14- Percepção sobre a participação dos pais dos alunos por tempo de trabalho na educação

\begin{tabular}{|l|r|r|r|}
\hline $\begin{array}{l}\text { O conselho escolar é } \\
\text { bastante atuante e define, } \\
\text { com a participação da } \\
\text { maioria de seus membros, o } \\
\text { orçamento da unidade } \\
\text { educacional }\end{array}$ & $\begin{array}{c}\text { Tempo } \\
\text { médio de } \\
\text { trabalho na } \\
\text { educação }\end{array}$ & \multicolumn{1}{|c|}{$\mathrm{N}$} & \\
\hline Concordo & 12,8 & 545 & Desvio padrão \\
Discordo & 12,8 & 289 & 8,7 \\
Indiferente & 12,4 & 123 & 8,9 \\
NR & 13,4 & 138 & 9,1 \\
Total & 12,8 & 1095 & 9,4 \\
\hline
\end{tabular}

Fonte: Pesquisa TDEBB, 2009/2010. Obs.: NR = Não resposta, não se aplica, não sabe.

Tabela 15- Percepção sobre o conselho escolar por tempo de trabalho na educação

\begin{tabular}{|l|r|r|r|}
\hline $\begin{array}{l}\text { O conselho escolar é } \\
\text { bastante atuante e define, } \\
\text { com a participação da } \\
\text { maioria de seus membros, o } \\
\text { orçamento da unidade } \\
\text { educacional }\end{array}$ & $\begin{array}{c}\text { Tempo } \\
\text { médio de } \\
\text { trabalho na } \\
\text { educação }\end{array}$ & $\mathrm{N}$ & \\
\hline Concordo & 12,8 & 545 & Desvio padrão \\
Discordo & 12,8 & 289 & 8,7 \\
Indiferente & 12,4 & 123 & 8,9 \\
NR & 13,4 & 138 & 9,1 \\
Total & 12,8 & 1095 & 9,4 \\
\hline
\end{tabular}

Fonte: Pesquisa TDEBB, 2009/2010. Obs.: NR = Não resposta, não se aplica, não sabe. 


\section{Conclusões}

Este texto buscou apresentar os primeiros achados acerca da percepção sobre a gestão escolar pelos docentes da educação básica pública no estado do Paraná. Não se pode tomar tal percepção como expressão última da realidade, mas, mesmo assim, trata-se de informações importantes para se conhecer mais e melhor as escolas e seus modos de organização e gestão.

Vimos que os docentes das escolas municipais e os mais experientes tendem a fazer uma avaliação mais positiva quanto à democracia nas escolas onde atuam do que os da rede estadual ou os com menos tempo de trabalho na educação. Ainda que seja possível que tais elementos derivem de vieses próprios da amostra em tela, é interessante se observar que os trabalhadores da rede estadual apresentam uma leitura mais crítica ou pessimista do fenômeno e isto pode ter relação com as constantes variações no modelo de gestão escolar adotado pela secretaria estadual, que ao longo das últimas duas décadas ora priorizou os conselhos escolares, ora as associações de pais e mestres, ora as parcerias com instituições privadas; ou ainda, ora adotou eleições diretas para diretor, ora eleições indiretas, ora fez uma seleção prévia para depois se realizar eleições. Mas, também tal perspectiva pode ser derivada da menor interação e envolvimento dos docentes estaduais com a escola institucionalmente, problema este que é fruto, dentre outros motivos, do modelo de contratação adotado pela secretaria estadual.

De outro lado vimos que para os docentes municipais a autoridade do diretor escolar é mais evidente e forte. Isso pode ter relação com a proximidade (física e política) do dirigente escolar em relação à administração do sistema de ensino, que lhe cobra mais enfática e diretamente. Também é possível, conforme vimos, que isso seja decorrente do perfil docente das escolas municipais, que se destacam das estaduais pelo tipo de atendimento escolar e, consequentemente, pelo tipo de docente que demandam.

A criticidade também foi uma hipótese aventada para se explicar determinadas variações no grupo amostrado nesta pesquisa. Por vezes, articulada à experiência profissional, por vezes ao perfil da rede de ensino e, de maneira mais incisiva, 
à experiência política (seja partidária, seja sindical), a leitura que os docentes fazem sobre o desenvolvimento da gestão democrática parece depender do nível de avaliação crítica que eles acumularam ao longo de suas trajetórias profissionais e de suas vidas.

Por fim, outro aspecto que este estudo mostrou foi que a face administrativa da função do diretor escolar parece estar menos evidente do que mostravam estudos anteriores. Todavia, há ainda grande expectativa entre os docentes acerca da necessidade dos diretores escolares terem formação específica para atuação. Tais elementos parecem contraditórios, pois, uma vez que metade dos docentes não vê que o diretor tem atuado predominantemente nas funções administrativas, qual formação específica ele necessitaria? Colocando de outra forma: se a função do diretor escolar é dominantemente (político) pedagógica, sua formação como educador não é suficiente para o desempenho do seu trabalho?

A resposta a essas e outras questões não parece possível no âmbito deste estudo, uma vez que o foco da investigação esteve centrado no levantamento da percepção dos docentes sobre a gestão. É necessária a elaboração de estudos mais focalizados, por meio de estudos de caso em escolas públicas, de maneira a se cotejar tais percepções com a organização e gestão efetiva das escolas e, assim, conseguir avaliar mais qualificadamente a realidade do fenômeno. E isto já é outro estudo, que em fase futura deverá ser desenvolvido.

\section{Notas}

"Este artigo expressa parte dos achados das pesquisas: "Trabalho Docente na Educação Básica no Brasil", coordenado pelo MESTRADO/UFMG e financiado pela SEB/MEC; "Gestão da escola pública no Brasil: as relações do perfil dos dirigentes e dos processos de gestão com os resultados do trabalho escolar", financiado pelo CNPq.

${ }^{* *}$ Doutor em Educação. Professor e Pesquisador do Núcleo de Políticas Educacionais (NuPE) e do Programa de Pós-Graduação em Educação (PPGE) da Universidade Federal do Paraná (UFPR). angelo@ufpr.br. 
${ }^{1}$ Para mais informações sobre a pesquisa nacional, acesso www.trabalhodocente. net.br.

${ }^{2} 8 \%$ dos docentes paranaenses afirmam ser filiados a partido político e $34 \%$ afirmam ser filiados a um sindicato.

\section{Referências Bibliográficas}

LITTRELL, J.; FOSTER, W. The myth of a knowledge base in educational administration. In: DONMOYER, R.; IMBER, M.; SCHEURICH, J.J. 1995. The knowledge base in educational administration: multiples perspectives. Albany/EUA: State University of New York, 1995.

SOUZA, A. A natureza política da gestão escolar e as disputas pelo poder na escola. Revista Brasileira de Educação, vol.17, n. 49, Rio de Janeiro, mar./abr. 2012.

A Produção do Conhecimento e o Ensino da Gestão

Educacional no Brasil. Revista Brasileira de Política e Administração da Educação, vol. 24, p. 51-62, 2008.

. Perfil da Gestão Escolar no Brasil. 2007. Tese de Doutorado (Educação: História, Política, Sociedade), Pontífice Universidade Católica de São Paulo, São Paulo, 2007.

TEIXEIRA, M. A. P. Formação para diretor escolar da educação básica: o programa nacional escola de gestores no estado do Paraná. 2011. Dissertação (Mestrado em Educação) - Universidade Federal do Paraná, [s.1.], 2011. 